\title{
Self-Knowledge of an Amnesic Patient: Toward a Neuropsychology of Personality and Social Psychology
}

\author{
Stanley B. Klein and Judith Loftus \\ University of California, Santa Barbara
}

\author{
John F. Kihlstrom \\ Yale University
}

\begin{abstract}
The authors present the case of W.J., who, as a result of a head injury, temporarily lost access to her episodic memory. W.J. was asked both during her amnesia and following its resolution to make trait judgments about herself. Because her responses when she could access episodic memories were consistent with her responses when she could not, the authors conclude that the loss of episodic memory did not greatly affect the availability of her trait self-knowledge. The authors discuss how neuropsychological evidence can contribute to theorizing about personality and social processes.
\end{abstract}

In recent years, cognitive science has demonstrated the usefulness of neuropsychological data to psychological theorists (for reviews, see Kinsbourne, 1987; Polster, Nadel, \& Schacter, 1991; Schacter \& Tulving, 1994). For example, studies of patients suffering amnesia as a result of head injury reveal a dissociation between episodic and semantic memory that suggests the existence of two distinct systems (e.g., Grossi, Trojano, Grasso, \& Orsini, 1988; Tulving, $1989,1991)$; similarly, studies of imagery in brain-damaged individuals has suggested that visual imagery and spatial imagery are mediated by different systems and are thus not identical (e.g., Farah, 1988; Jankowiak, Kinsbourne, Shalev, \& Bachman, 1992; Vargha-Khadem, Issacs, \& Mishkin, 1994).

For social and personality psychologists, however, the study of patients with neuropsychological impairments has rarely been undertaken. In this article we offer the case of W.J., who suffered profound retrograde amnesia following a head injury, as a demonstration of the way in which questions of interest to social and personality psychologists can be addressed with neurological data. Specifically, our tests of W.J. have provided us with data, unobtainable from individuals with no memory loss, that is pertinent to the debate over the relation between knowledge of traits and memory for specific personal events relevant to those traits.

Stanley B. Klein and Judith Loftus, Department of Psychology, University of California, Santa Barbara; John F. Kihlstrom, Department of Psychology, Yale University.

This work was supported by an Academic Senate Research Grant from the University of California, Santa Barbara, and by National Institute of Mental Health Grant MH-35856a.

We wish to thank Leda Cosmides, John Tooby, and Endel Tulving for their many insightful comments and suggestions.

Correspondence concerning this article should be addressed to Stanley B. Klein, Department of Psychology, University of California, Santa Barbara, California 93106.
The Role of Episodic and Semantic Memory in Trait Self-Knowledge

Does a person's knowledge of his or her own traits depend on an ability to recall his or her own past behavior? Is it possible for a person who cannot recall any personal experiences-and therefore cannot know how he or she behaved-to know what he or she is like? Questions such as these have stimulated debate among philosophers (e.g., Grice, 1941; Hume, 1739/1817; Locke, 1690/1731; Shoemaker, 1963) and psychologists (e.g., Buss \& Craik, 1983; James, 1890; Klein \& Loftus, 1993b; Locksley \& Lenauer, 1981) for more than 300 years. Unfortunately, as evidenced by the number of years that debate on this topic has persisted, the question of whether trait knowledge is inseparable from memory for past behavior has proven difficult to answer. In this article we make a modest contribution to this debate by demonstrating that an individual can have detailed and accurate knowledge of her traits despite having little if any conscious access to behavioral memories from which she could infer that knowledge.

Knowledge of personality traits and recollections of specific personal events involving those traits can be considered examples of two types of knowledge about the self: semantic personal knowledge and episodic personal knowledge (e.g., Cermak, 1984; Conway, 1987; Evans, Wilson, Wraight, \& Hodges, 1993; Kihlstrom et al., 1988; Kihlstrom \& Klein, 1994, in press; Klein \& Loftus, 1993b; Klein, Loftus, \& Sherman, 1993; Kopelman, 1994; Neisser, 1986; Tulving, 1989, 1993; Tulving, Schacter, McLachlan, \& Moscovitch, 1988; Van der Linden, Bredart, Depoorter, \& Coyette, 1996). Semantic personal knowledge is information that has been abstracted from memories of the self in specific events (e.g., Klein \& Loftus, 1993b; Neisser, 1986; Tulving, 1989, 1993; Tulving et al., 1988). Thus, semantic personal knowledge of traits might include the facts that a person is kind, outgoing, and lazy. Episodic personal knowledge, by contrast, consists of memories of specific events involving the self (e.g., Cermak, 1984; Conway, 1987; Klein \& Loftus, 1993b; Tulving, 1983, 1989, 1993). 
Thus, episodic personal knowledge of traits could include memories of instances in which behavior was kind, outgoing, or lazy.

Our previous research with individuals with no memory loss used a number of techniques to examine the relation between these two types of trait knowledge about the self. Our data consistently have supported the view that in the realm of trait knowledge, semantic personal memory and episodic personal memory are functionally independent, by which we mean that the operations of semantic personal memory do not require the operations of episodic personal memory (for reviews, see Kihlstrom \& Klein, 1994, in press; Klein \& Loftus, 1993b).

In our initial investigations of the relation between semantic and episodic memory for traits, we used a priming paradigm. In a series of studies, we found that participants who made self-descriptiveness judgments about trait words were no faster than participants who performed a control task to then perform a second task that required them to retrieve personal episodic memories about the same traits (Klein \& Loftus, 1990b, 1993a, 1993b; Klein, Loftus, \& Burton, 1989, Experiment 2; Klein et al., 1993; Klein, Loftus, Trafton, \& Fuhrman, 1992, Experiments 2, 3, \& 4; Schell, Klein, \& Babey, 1996). We concluded from this that the semantic personal knowledge required for a self-descriptiveness judgment was accessed without activating episodic personal memories. If episodic memories had been activated during the self-descriptiveness judgments, then participants who made those judgments should have had an advantage over participants who performed the control task in the speed with which they subsequently retrieved episodic memories.

We have conducted several other studies of trait selfknowledge that also support the independence of semantic and episodic personal memory. Klein, Loftus, and Plog (1992), for example, made use of the phenomenon of transfer-appropriate processing (e.g., Roediger \& Blaxton, 1987; Roediger, Weldon, \& Challis, 1988) in a study of recognition memory for traits to show that different processes are involved in accessing the two types of memory. In addition, Klein et al. (1989, Experiment 4) applied the principle of encoding variability (e.g., Bower, 1972; Martin, 1971, 1972) in a study of recall for traits and found that the type of information made available by accessing semantic personal memory was different from that made available by accessing episodic personal memory.

However, although this research converges in support of the functional independence of semantic and episodic trait knowledge of self, a number of theorists have noted a problem inherent in trying to infer the functional independence of semantic and episodic memory from the performance of individuals with no memory loss (e.g., Parkin, 1993; Tulving, Hayman, \& Macdonald, 1991). Specifically, experiments that attempt to demonstrate such independence must be able to show that each of these memory systems can operate without the other-that participants can perform a task involving one memory system without activating the other. However, when participants have access to both episodic and semantic memory, it is difficult to rule out interplay between the two systems in the performance of experimental tasks and therefore difficult to compellingly demonstrate that the two systems are independent. For example, although Klein et al. (1989, Experiment 2; see also Klein et al., 1992, Experiments 2, 3, \& 4) found that participants appeared to make self-descriptiveness judgments without retrieving episodic memories, it is possible that episodes were retrieved but that the tests used to detect retrieval were not sufficiently sensitive (for a discussion of this possibility, see Keenan, 1993).

However, amnesic memory impairment offers an opportunity to overcome this problem. Amnesic patients provide a particularly effective method for testing the independence of semantic and episodic personal memory, because these patients typically display intact semantic memory with impaired access to episodic memory (e.g., Cermak, 1984; Evans et al., 1993; Kinsbourne \& Wood, 1975; Schacter \& Tulving, 1982; Tulving, 1989, 1991, 1993; Tulving et al., 1988; Tulving et al., 1991; Wood, Ebert, \& Kinsbourne, 1982; but see Zola-Morgan, Cohen, \& Squire, 1983, for a dissenting view). Therefore, it is possible with amnesic patients to test semantic self-knowledge of traits with assurance that episodic memory for traits is not involved. If the two systems are indeed functionally independent, then amnesic patients should be able to make trait self-descriptiveness judgments despite their inability to recall personal events.

This hypothesis has been tested by Tulving (1993). Tulving found that the patient K.C., whose entire fund of episodic memory was permanently lost following a motorcycle accident, was able to describe his personality with considerable accuracy. Tulving asked K.C. on two occasions to rate a list of trait adjectives for self-descriptiveness. Tulving also asked K.C.'s mother to rate K.C. on the same traits. Tulving's findings revealed that K.C.'s ratings were both reliable (K.C.'s trait self-ratings showed $78 \%$ agreement across sessions) and consistent with the way he is perceived by others (there was $73 \%$ agreement between K.C.'s and his mother's ratings of K.C.'s traits). K.C. thus appears to have accurate and detailed knowledge about his personality despite the fact that he has no conscious access to any behavioral episodes from which he could infer this knowledge.

The fact that K.C., without access to episodic self-knowledge, can access semantic self-knowledge to make trait self-descriptiveness judgments confirms that semantic personal memory is functionally independent of episodic personal memory in the realm of trait knowledge. Having established this, however, a question still remains. Although K.C.'s case shows that semantic personal memory can function without episodic personal memory, does this mean that under ordinary circumstances the two types of memory do not interact? K.C. can make trait judgments; but perhaps his judgments would be different if his episodic memory were intact (for a discussion, see Schneider, Roediger, \& Khan, 1993).

To this question we bring the case of W.J., who, as a result of a head injury, suffered temporary retrograde amnesia. Retrograde amnesia is the inability to recall events that precede the onset of the amnesia. Typically, it entails 
loss of episodic memory with sparing of semantic memory (e.g., F. C. Goldstein, Levin, \& Boake, 1989; Levin et al., 1985; Lucchelli, Muggia, \& Spinnler, 1995; Schacter \& Tulving, 1982; Tulving et al., 1991; Van der Linden et al., 1996; Wood et al., 1982). When it occurs following a closed-head injury, retrograde amnesia typically has the additional feature of being temporary, resolving in the days or weeks following the injury (e.g., Blomert \& Sisler, 1974; Russell, 1971; Sisler \& Penner, 1975; Whitty \& Zangwill, 1977).

Because W.J.'s amnesia was temporary, it was possible to test her semantic personal memory both without and with access to episodic personal memory. We asked W.J. to make trait judgments about herself during the time when she was amnesic for events pertaining to those judgments and again when her episodic memory had returned. In this way, we were able to look for differences in her semantic memory performance as a function of the accessibility of episodic memory. Performance differences would tell us that semantic and episodic personal memory, although functionally independent, do interact in some way. However, consistent performance without and with episodic memory would point toward a stronger form of independence between the two memory types.

\section{Method}

\section{Participants}

\section{Patient W.J.}

The patient, W.J., is an 18-year-old female undergraduate. During the first week of her second quarter at college she sustained a concussional head injury as a result of a fall. After complaining of a headache and difficulty in concentration and memory, she was taken to a hospital emergency room where a computerized tomography brain scan was performed. No signs of neurological abnormality were observed.

W.J. was interviewed by Stanley B. Klein on several occasions. In a meeting $\mathbf{5}$ days after her head injury, she complained of great difficulty remembering events that occurred before the accident. Questioned informally, she was unable to bring to mind a single personal event or experience from the last 6-7 months of her life - a period of time covering approximately her first quarter at college. Her memory for more remote personal events was patchy, with amnesic gaps dating back to about 4 years before her injury.

Despite her dense retrograde amnesia for events from the preceding 6-7 months, W.J.'s memory for general facts about her personal life during that period seemed largely intact. She knew, for example, which classes she attended during her first quarter at college, although she could not remember a specific occasion when she attended class or a specific event that happened during a class; she knew the names of teachers and friends from college, although she could not remember particular experiences shared with them.

W.J. also showed a moderate degree of anterograde memory impairment, which seemed limited to the period of approximately 45 min following her fall. Although her boyfriend reported that she was conscious and coherent, W.J. had no recollection of events that occurred during that time.

Eleven days after the accident, W.J.'s retrograde amnesia had cleared considerably. Her memory impairment appeared limited to events from the last 6 months, and within that period she was able to clearly recollect a number of incidents. For example, she could describe in great detail a visit to the home of her boyfriend's parents 3 months earlier. Her anterograde amnesia, on the other hand, remained unchanged.

When interviewed 3 weeks later, W.J. appeared to have completely recovered her memory for events preceding her fall. She still, however, was unable to recall events that occurred immediately afterward.

\section{Control Participants With No Memory Loss}

Control group for memory testing. Three female undergraduates, whose mean age ( 19 years, 4 months) was closely matched to W.J.'s age (18 years, 3 months), were tested on the same battery of memory tests that was administered to W.J.

Control group for personality testing. Two opposite-sex couples, whose arrival at college coincided with W.J.'s (6 months prior to testing) and whose mean time as a couple (4.2 years) closely matched that of W.J. and her boyfriend (3.5 years), completed the same personality trait questionnaire that was completed by W.J. and her boyfriend.

\section{Procedure}

\section{Memory Testing}

Memory performance following closed-head injury follows a fairly consistent pattern of preserved and impaired function (for reviews, see Levin, 1989; Russell, 1971; Russell \& Nathan, 1946; Schacter \& Crovitz, 1977; Whitty \& Zangwill, 1977). Immediate memory span and access to semantic knowledge typically are intact, whereas episodic memories of events preceding and following the injury are likely to be impaired. In most cases, the retrograde component of the amnesia shrinks in the days following the injury, with memories returning in a roughly chronological order from the most distant to the most recent events.

To evaluate W.J.'s memory function, we administered the following battery of memory tests to her and to three female control participants. Except where indicated, all testing was conducted 5 days after W.J. had sustained her head injury. Participants were tested individually.

Digit span. W.J.'s immediate memory was assessed using a digit-span technique (e.g., Watkins, 1977). An experimenter read aloud to the participant a list of digits, at a rate of one digit every $2 \mathrm{~s}$, beginning with a list of two digits. The participant then was to immediately repeat the digits back to the experimenter in correct order. If the list was repeated correctly, the experimenter read another list of digits, increasing the length of the list by one digit. Testing continued until the participant failed to repeat a list correctly. The procedure then was repeated with new lists and a change in instructions so that participants repeated the digits in reverse order, rather than in presentation order.

Free recall. W.J.'s ability to retain information beyond the span of immediate memory was examined using a free-recall paradigm. Participants were presented with five lists of 16 unrelated nouns. Each list was read aloud by the experimenter at the rate of 1 noun every $2 \mathrm{~s}$. Immediately after presentation of the last item in a list, participants were given 1 min to write as many of the items from that list as possible, in any order. Each participant's recall performance was plotted as a serial-position curve, which shows the probability of an item being correctly recalled as a function of its serial position in the input list (e.g., Glanzer \& Cunitz, 1966; Murdock, 1962). 
Semantic memory. To investigate W.J.'s access to semantic knowledge, we selected two tasks-verbal fluency and category judgment-from the battery of semantic memory tests used by Wilson \& Baddeley (1988).

In the verbal fluency task, participants were required to generate as many items as possible from each of six semantic categories: animals, fruits, furniture, girls' names, birds, and metals. Participants were allowed $1 \mathrm{~min}$ per category in which to write responses.

In the category judgment task, participants were shown 24 pairs of words and, for each pair, were asked to decide whether the words belonged to the same semantic category (e.g., fruits, animals). Half of the pairs contained words from the same semantic category (e.g., grape-apple), and half contained words from different categories (e.g., tiger-boat). Participants were asked to state their decisions as quickly as possible, and their decision latencies were recorded.

Episodic memory. We used the autobiographical memory-cueing task originated by Galton (1879) and later modified by Crovitz and Schiffman (1974) and Robinson (1976) to test memory for personal episodes. In this task, participants were presented with cue words. For each cue, they were asked to recall a specific personal event and to provide as precise a date as possible for that event. For example, a participant might respond to the cue $d o g$ by recalling that she walked her dog that morning or that she received a dog as a gift for her 10th birthday.

Our study examined episodic memory under two cueing conditions: unconstrained and constrained (e.g., Schacter, Kihlstrom, Kihlstrom, \& Berren, 1989; Schacter, Wang, Tulving, \& Freedman, 1982). In the unconstrained condition, participants were read a list of 24 cue words, 1 word at a time. They were instructed to recall for each cue a specific personal event related to the cue from any time in their past. The 24 cues were common English words, randomly selected from the set of 48 cue words presented by Robinson (1976). The cues included 8 affect words (e.g., lonely, surprised), 8 object words (e.g., car, river) and 8 activity words (e.g., run, visit). All participants received the same set of 24 cue words in a fixed-random order.

At the beginning of the session, participants were told that we were interested in studying memory for personal events. They were informed that a series of words would be read to them and that they should try to think of a specific personal event that was related to each word. They were instructed to provide a brief verbal description of each memory and to date the memory as accurately as possible. If on any trial a participant was unable to retrieve a memory within $60 \mathrm{~s}$, the trial was terminated and the participant was read the next cue.

After a short rest break, the constrained-cueing task was administered. This task was identical to the unconstrained task, except that participants were instructed to restrict their recall to events that had occurred within the last 6 months. The same cues were used in the constrained and unconstrained conditions.

In a second session, conducted 4 weeks after the first session, participants were tested again using only the unconstrained-cueing condition.

\section{Personality Testing}

A list of 80 trait adjectives was selected from Kirby \& Gardner's (1972) norms to create a personality questionnaire. The adjectives selected were close to the norm means on the dimensions of familiarity, imagery, and behavioral specificity and spanned the range of social desirability. The questionnaire consisted of four sheets of paper with 20 traits per sheet. Beside each trait were four choices: not at all, somewhat, quite a bit, and definitely.
Personality testing was conducted in two sessions. The first session took place 5 days after W.J.'s accident. W.J. was provided with a personality questionnaire and was instructed to indicate, by circling the appropriate choice, the extent to which each trait described her since her arrival at college. Her boyfriend also completed the questionnaire, indicating for each trait how well it described W.J. since her arrival at college. After a brief break, W.J. filled out the questionnaire a second time, this time indicating for each trait the extent to which it described her during high school.

Two control couples also completed the questionnaire. For each couple, the woman indicated how well each of the 80 trait adjectives on the questionnaire described her since her arrival at college, and the man indicated the extent to which the traits described his partner since her arrival at college.

A second session was conducted 4 weeks later. W.J. and the two women of the control couples again were given the personality questionnaire and asked, for each trait, to indicate how well it described them since their arrival at college.

\section{Results}

\section{Memory Testing}

\section{Digit Span}

Immediate memory, as measured by the digit span, typically is normal in patients who have suffered closed-head injuries (e.g., Brooks, 1975; Schacter \& Crovitz, 1977). W.J.'s digit-span performance ( 5 digits forward and 5 digits backward) was comparable to that of the control participants ( $M$ s $=5.3$ digits forward and 5.7 digits backward). This suggests that W.J. can hold as much information in immediate memory as can control participants with no memory loss.

\section{Free Recall}

Figure 1 shows two serial-position curves: one for W.J. and one representing the mean performance of the control participants. As can be seen, there is little difference be-

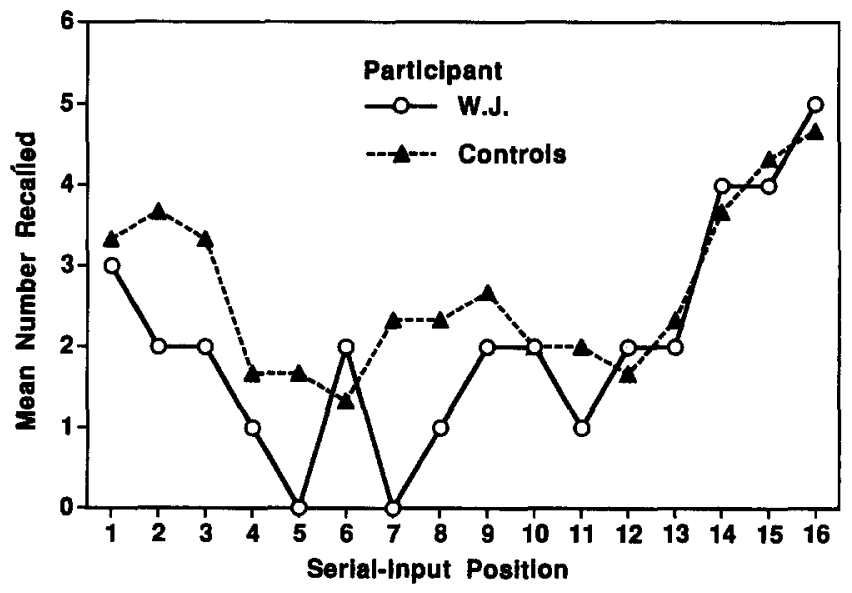

Figure 1. Serial-position curve, showing mean number of nouns recalled by W.J. and control participants with no memory loss as a function of serial-input position. 
tween the curves. For both, items from the beginning and end of the list were better recalled than were items in the middle, resulting in the U-shaped curve characteristic of normal free-recall performance (e.g., Glanzer \& Cunitz, 1966; Murdock, 1962; Waugh \& Norman, 1965). These findings parallel those of Brooks (1975), who found no reliable difference between head-injury and control participants in immediate free recall of words as a function of their presentation position in a list.

\section{Semantic Memory}

Amnesic patients usually perform normally or near normally on tasks requiring access to knowledge contained in semantic memory (e.g., Cermak, 1984; Cermak \& O'Connor, 1983; Kinsbourne \& Wood, 1975; Lucchelli et al., 1995; Schacter \& Tulving, 1982; Wilson \& Baddeley, 1988; Wood et al., 1982). The results of the verbal-fluency and category-judgment tests are shown in Table 1. W.J.'s performance on both tests was within the range established by the control participants, indicating that the speed and accuracy with which she could access material from semantic memory was unimpaired.

\section{Episodic Memory}

Retrograde amnesia for personal episodes commonly is observed in cases of closed-head injury (e.g., Blomert \& Sisler, 1974; Russell, 1971; Russell \& Nathan, 1946; Schacter \& Crovitz, 1977; Sisler \& Penner, 1975; Whitty \& Zangwill, 1977; Williams \& Zangwill, 1952; Yarnell \& Lynch, 1970). Figure 2 presents the proportion of episodic memories produced from four different time periods: from within the previous 12 months, from more than a year but less than 5 years ago, from more than 5 but less than 10 years ago, and from more than 10 years ago.

The temporal distributions of memories produced during the first unconstrained-cueing session are shown in Figure $2 \mathrm{~A}$. As can be seen, there is a marked difference between the performance of W.J. and that of the controls. Paralleling previous studies of participants with no memory loss (e.g., Crovitz \& Quina-Holland, 1976; Crovitz \& Shiffman, 1974; Rubin, 1982; Rubin, Wetzler, \& Nebes, 1986), control participants showed a pronounced recency bias in their recall: The majority of memories came from the most recent 12 -

Table 1

Semantic Memory Performance

\begin{tabular}{|c|c|c|c|}
\hline \multirow[b]{2}{*}{ Tests } & \multicolumn{2}{|c|}{ Participants } & \multirow{2}{*}{$\begin{array}{l}S D \text { of } \\
\text { controls }\end{array}$} \\
\hline & W.J. & Controls & \\
\hline \multicolumn{4}{|l|}{ Category judgment } \\
\hline$M$ per judgment (s) & .99 & .82 & .26 \\
\hline Errors per 24 word pairs & 1.00 & .33 & - \\
\hline \multicolumn{4}{|l|}{$\begin{array}{l}\text { Verbal fluency (mean items } \\
\text { generated) }\end{array}$} \\
\hline $30 \mathrm{~s}$ & 8.50 & 7.83 & 1.21 \\
\hline $1 \mathrm{~min}$ & 11.33 & 11.89 & 1.67 \\
\hline
\end{tabular}

month period $(65 \%)$, with increasingly smaller proportions recalled from each of the more distant past periods.

By contrast, W.J.'s recall was characterized by a strong primacy bias: She had considerable difficulty retrieving memories from the previous 12 months (she could recall only a single episode from the last year and none from the last 6 months) and progressively less difficulty retrieving memories from earlier periods. The temporal gradient found in W.J.'s recall fits nicely with a growing body of evidence showing that following closed-head injury, disruption of memory retrieval is more likely to be seen for recently acquired memories than for older memories (e.g., Baddeley \& Wilson, 1986; Cermak, 1984; Hodges \& Ward, 1989; Levin et al., 1985; Lucchelli et al., 1995; MacKinnon \& Squire, 1989; Ribot, 1882; Russell, 1935; Russell \& Nathan, 1946; Zola-Morgan et al., 1983).

Although W.J.'s performance on the first unconstrained autobiographical cueing task indicates that she was densely amnesic for recent personal episodes, several investigators have noted that caution must be exercised when interpreting results from this task (e.g., Evans et al., 1993; Kopelman, 1994; Kopelman, Wilson, \& Baddeley, 1989). Because W.J. was not required to produce memories from specified time periods, it is difficult to know whether her failure to retrieve personal memories from the last 6 months reflects an inability to do so or, rather, a bias to sample from more remote time periods.

The constrained autobiographical cueing task allowed us to distinguish between these alternatives by requiring participants to restrict their recall to memories of events occurring in the previous 6 months. In this condition, W.J. was unable to retrieve a single memory. By contrast, control participants produced memories in response to $96 \%$ of the cues. These data clearly suggest that W.J.'s failure to produce recent episodic memories in the unconstrained-cueing task represents a retrieval impairment rather than a bias in sampling.

Figure $2 \mathrm{~B}$ presents the results from the second unconstrained-cueing session, conducted 4 weeks after the first. As noted previously, informal questioning indicated that W.J.'s retrograde amnesia largely had cleared at this point. Consistent with this observation, W.J. and control participants produced virtually identical temporal distributions of memories, characterized by pronounced recency biases (83\% and $77 \%$ of the memories retrieved by W.J. and the controls, respectively, came from the 12 months preceding the test). It should be noted that W.J.'s recency bias was not due to recall of events occurring during the 4-week period following initial testing: Only 2 of the 20 memories she dated as having occurred during the last year were drawn from that period. These data, then, demonstrate a substantial recovery of W.J.'s episodic memory by the second testing session.

\section{Personality Testing}

The central question for the present research is whether semantic self-knowledge is independent of episodic selfknowledge. To examine this question, we had W.J. make 
A

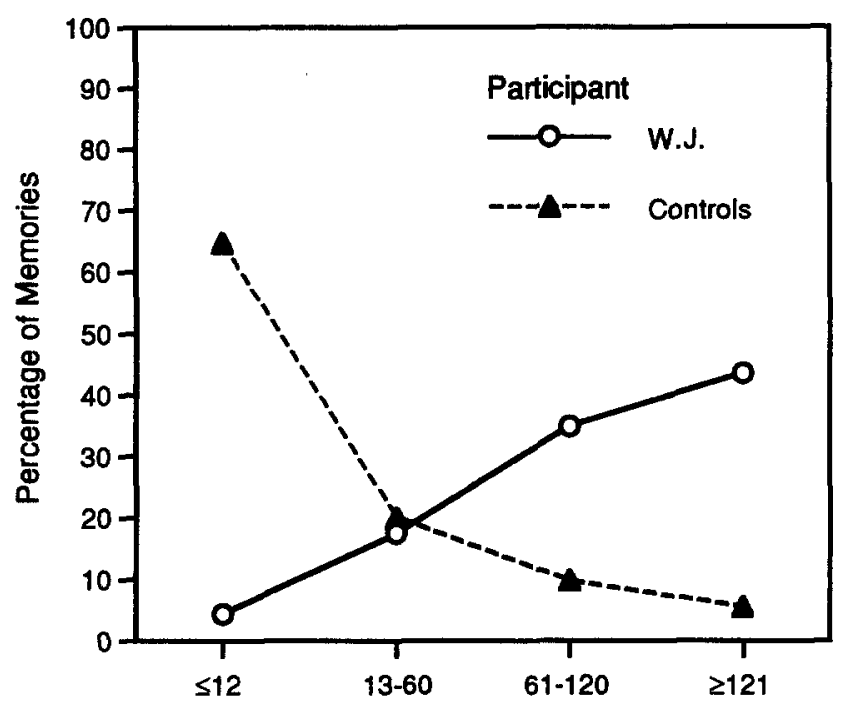

Age of Memories in Months

B

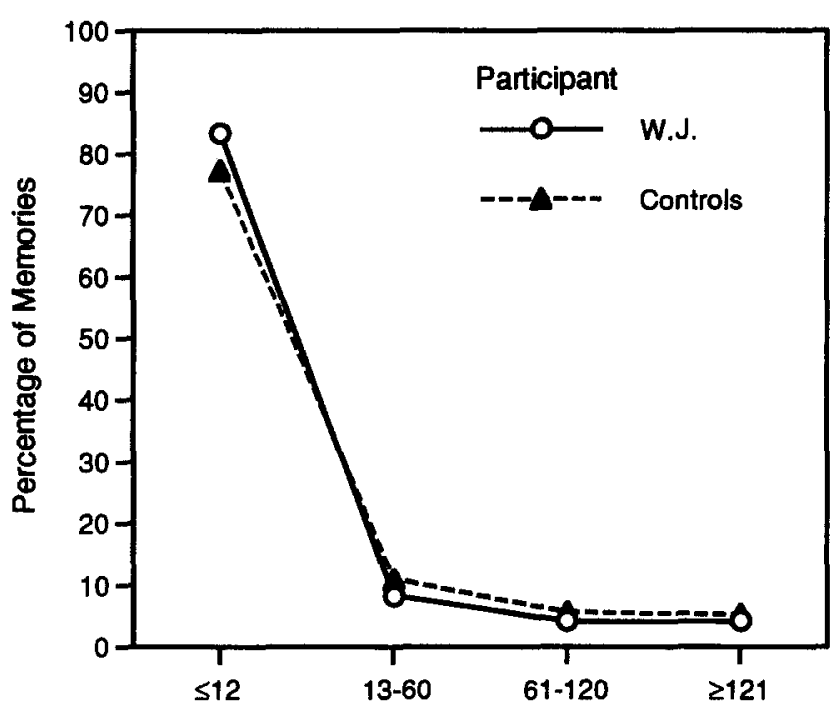

Age of Memories in Months

Figure 2. Percentage of episodic memories in four age periods produced by W.J. and control participants with no memory loss with unconstrained cueing during Session 1 (A) and Session 2 (B).

trait ratings of herself at college both during her amnesia and following its resolution. We reasoned that if semantic knowledge of one's traits is not dependent on access to trait-related episodic memories, then W.J.'s trait self-ratings should be unaffected by changes in the accessibility of her episodic memories.
We asked W.J. on two occasions to provide ratings of herself at college. The first rating session took place while she was densely amnesic for personal events that had occurred during college; the second session occurred after her memory for her experiences at college had fully recovered. Two female controls provided trait ratings of themselves at college during the same two sessions.

W.J.'s ratings of herself at college showed considerable consistency across testings: The Pearson product-moment correlation coefficient between ratings produced in the first and second session was significant $(r=.74, p<.05)$ and virtually identical to that for the control participants ( $r=$ $.78, p<.05$ ). Thus, despite a dramatic change in the accessibility of her episodic memories of herself at college across testings, W.J.'s test-retest reliability was comparable to that of participants who had access to episodic memories at both testings. It appears that W.J.'s loss of episodic memory did not affect access to her trait self-knowledge.

It is, of course, possible that W.J.'s ratings agreed over sessions because she simply endorsed positive traits and rejected negative traits on both trials (e.g., Edwards, 1970; Wiggins, 1968). To address this concern, we compared W.J.'s self-ratings from the first session with ratings of her made by her boyfriend. Research has shown that the social desirability of traits is far less likely to influence ratings made by an external assessor who knows the person well (e.g., McCrae, 1982; Wiggins, 1973). Therefore, if W.J. were basing her ratings on social desirability, we would not expect a strong correlation between her ratings and ratings of her provided by her boyfriend. However, the correlation between W.J.'s self-ratings and those made by her boyfriend was significant $(r=.65, p<.05)$ and did not differ from that obtained from control couples $(r=.65, p<.05)$. Thus, we conclude that W.J.'s self-ratings could not be based purely on social desirability.

An item-by-item analysis of W.J.'s trait ratings provides additional support for this conclusion. Of the 80 trait ratings made by W.J., 19 traits with socially undesirable features (e.g., boring, undependable) were endorsed as self-descriptive, and 8 traits with socially desirable features (e.g., sociable, polite) were rejected as non-self-descriptive.

Another concern is whether W.J.'s ratings of herself at college were, in fact, based on knowledge of herself during her 6 months at college. It is conceivable, for example, that during initial testing W.J. was unable to access any selfknowledge from the last 6-7 months. Under these circumstances, she may have adopted a strategy of retrieving memories from the most recent period for which she had accessible self-knowledge (i.e., high school) to make reasonable guesses about what she was like at college. Since trait self-descriptions tend to be relatively stable by adolescence (e.g., Engel, 1959; Mortimer \& Lorence, 1981; O'Malley \& Bachman, 1983), some agreement between ratings based on knowledge of the self in the high-school and college contexts would not be surprising.

To address this concern, we asked W.J. during the first test session to rate how she saw herself during high school. We then computed the correlation between her ratings of herself at high school and her postamnesia ratings of herself at college. 
We compared this correlation with the correlation between her ratings of herself at college across sessions.

We predicted that if W.J. had access to knowledge of herself at college during her amnesia, then the correlation between her ratings of herself at high school and her postamnesia ratings of herself at college would be lower than the correlation between her ratings of herself at college across testings. By contrast, if, during her amnesia, W.J. actually based her trait ratings of herself at college on knowledge of what she was like in high school, then the correlation between her ratings of herself at high school and her postamnesia ratings of herself at college should be comparable to that obtained between her ratings of herself at college across sessions.

Statistical analyses revealed that the correlation between her ratings of herself at high school and her postamnesia ratings of herself at college was significant $(r=.53, p<$ .05 ), meaning that some degree of reliability in W.J.'s ratings of her college self could have been achieved by reliance on her memories of her precollege behavior and experiences. However, this figure was significantly lower than the correlation obtained between W.J.'s ratings of herself at college across sessions $(r=.74), t(158)=1.71$, $p<.05$, one-tailed. So, there is reliable variability in her college self that is not accounted for by her high-school self. Put another way, while she was amnesic, W.J. knew something about what she had been like at college, which was different from what she was like in high school; but she knew this despite the fact that she could not recall anything from her time in college.

\section{Discussion}

This experimental case study illustrates some of the ways in which theoretical issues of concern to personality and social psychologists, especially those surrounding the self, can be addressed with neurological data.

W.J., a college freshman, suffered a concussive blow to the head in the winter quarter of 1995. As a result of this injury, she showed a profound retrograde amnesia for events that had transpired over the 6 months immediately prior to the accident. Over the next month, this amnesia remitted completely. W.J.'s amnesic deficit in episodic personal memory was documented by the Crovitz-Robinson technique of cued autobiographical recall. When tested 5 days after the accident, under both free and constrained conditions, W.J.'s performance was clearly impaired compared with that of a group of participants with no memory loss. Four weeks later, W.J.'s performance had improved considerably and was indistinguishable from that of controls.

In contrast to the impairment and recovery of episodic memory, W.J.'s self-ratings of personality did not change at all over the same period of time: Her self-ratings made during the amnesic period agreed with those she made afterward.

The fact that W.J.'s episodic personal memories were affected by the concussion, but her semantic personal memories were not, is evidence that these two types of selfknowledge are represented independently and perhaps me- diated by separate cognitive systems. Admittedly, it remains possible that W.J.'s ratings of her personality were based on episodic memories from high school (or earlier) that were not covered by the amnesia or on knowledge of what her personality was like before she entered college. Additionally, it is possible that the trait cues used for personality testing may have retrieved some episodic memories that were not retrieved by means of the affect, object, and activity cue words from the autobiographical memory-cueing task. One problem with neuropsychological evidence, from the investigator's point of view, is that the deficits in question rarely are complete. Still, the evidence obtained in this case is consistent with the results from K.C., the amnesic patient studied by Tulving (1993) and with evidence from intact participants derived from several different paradigms (for reviews, see Kihlstrom \& Klein, 1994; Klein \& Loftus, 1993b). Moreover, this evidence about the self is consistent with conclusions derived from studies of person memory (e.g., Allen \& Ebbesen, 1981; Anderson, 1989; Carlston, 1980; Klein \& Loftus, 1990a; Sherman \& Klein, 1994; for a recent review, see Kihlstrom \& Hastie, in press). We believe that when considered as a whole, the evidence we have presented compels one to seriously entertain the possibility that semantic personal knowledge is represented in a manner that is independent of episodic personal knowledge.

An interesting, but as yet untested, implication of our proposal that episodic and semantic personal memory are functionally independent is that a person could have complete access to his or her episodic personal memories yet be unable to judge a list of trait adjectives for self-descriptiveness. If such a case could be found, it would provide strong converging evidence in support of the proposed independence of these two types of self-knowledge.

\section{A Neuropsychological Approach to Issues in Social and Personality Psychology}

Over and above this specific theoretical question, we hope that this case study will stimulate other personality and social psychologists to consider the theoretical promise of patients with neuropsychological impairments. Consider, as an example, the classic case of Phineas Gage, the 19thcentury railway worker who underwent profound personality changes following traumatic injury to the anterior portion of his cerebral cortex (for a detailed account of this case, see Macmillan, 1986). For more than a century, this case has served as the source of speculations about the role of the frontal lobes in emotion, personality, and social relations (e.g., Damasio \& Anderson, 1993), and it may be that data from frontal-lobe patients will help resolve the vexing question of the relations between cognition and emotion (e.g., Lazarus, 1984; Zajonc, 1980, 1984).

As another example, consider the face-that most social of stimuli. Patients with bilateral damage to the occipital lobe, especially in regions adjacent to the temporal lobe, show deficits in recognizing familiar faces (e.g., Damasio, Damasio, \& Van Hoesen, 1982). Although it is unclear how specific this deficit is (they may also have difficulty recog- 
nizing other specific objects), observation of these patients has fueled speculation that there are particular brain systems specialized for perceiving and recognizing faces. At the same time, neuropsychological studies have revealed that facial agnosia comes in a wide variety of different forms. On the basis of this evidence, Bruce and Young (1986; see also Burton \& Bruce, 1993) have suggested that face perception involves a number of separate processes-for example, encoding structural representations of the face that are both dependent and independent of viewpoint, analyzing facial expressions, analyzing facial gestures, recognizing sameness and difference across viewpoints, and attaching names to faces. This model can be tested in intact participants as well and provides a theoretical bridge between cognitive and social psychology.

Neuropsychological evidence also is relevant to questions of the self. For example, the patient H.M., who received a bilateral resection of his temporal lobes, has suffered a gross anterograde amnesia since the day of his operation in 1953 (Milner, Corkin, \& Teuber, 1968; Scoville \& Milner, 1957). Despite the physical changes wrought by 40 years of aging and the fact that he remembers nothing of what he has done or experienced in all that time, H.M. has preserved a continuity of identity. Studies of amnesic patients' interpersonal, emotional, and motivational lives promise to provide new perspectives on the relations of these functions with memory.

Other neurological patients, especially those suffering hemiplegia, hemianesthesia, and hemianopia, have no awareness of their deficits-a condition called anosognosia (for a review, see McGlynn \& Schacter, 1989). Given that anosognosic patients do not acknowledge their deficits, understanding how they make sense of their disabilities should shed new light on the process of causal attribution regarding the self (Kihlstrom \& Tobias, 1991).

\section{Conclusions}

In the past, cognitive psychologists have made good use of neuropsychological case material in developing theories about mental function (Gazzaniga, 1995; Heilman \& Valenstein, 1993; Kolb \& Whishaw, 1990). With rare exceptions, however (e.g., K. Goldstein, 1934/1995; Luria, 1966; Sacks, 1974, $1985,1995)$, neuropsychologists have seldom inquired into their patients' personal and social lives. And, whether for lack of interest or lack of access, personality and social psychologists have rarely studied the victims of brain damage. We hope that this situation changes, for it would seem that neurological patients have much to teach us about the psychological processes involved in forming, maintaining, and using mental representations of ourselves and other people.

\section{References}

Allen, R. B., \& Ebbesen, E. B. (1981). Cognitive processes in person perception: Retrieval of personality trait and behavioral information. Journal of Experimental Social Psychology, 17, 119-141.
Anderson, N. H. (1989). Functional memory and on-line attribution. In J. N. Bassili (Ed.), On-line cognition in person perception (pp. 175-220). Hillsdale, NJ: Erlbaum.

Baddeley, A. D., \& Wilson, B. (1986). Amnesia, autobiographical memory and confabulation. In D. Rubin (Ed.), Autobiographical memory (pp. 225-252). Cambridge, England: Cambridge University Press.

Blomert, D. M., \& Sisler, G. C. (1974). The measurement of retrograde post-traumatic amnesia. Canadian Psychiatric Association Journal, 19, 185-192.

Bower, G. H. (1972). Stimulus-sampling theory of encoding variability. In A. W. Melton \& E. Martin (Eds.), Coding processes in human memory (pp. 85-123). Washington, DC: Winston.

Brooks, N. D. (1975). Long and short term memory in head injured patients. Cortex, 11, 329-340.

Bruce, V., \& Young, A. W. (1986). Understanding face recognition. British Journal of Psychology, 77, 305-327.

Burton, A. M., \& Bruce, V. (1993). Naming faces and naming names: Exploring an interactive activation model of person recognition. Memory, 1, 457-480.

Buss, D. M., \& Craik, K. H. (1983). The act frequency approach to personality. Psychological Review, 90, 105-126.

Carlston, D. E. (1980). The recall and use of traits and events in social inference processes. Journal of Experimental Social Psychology, 16, 303-328.

Cermak, L. S. (1984). The episodic-semantic distinction in amnesia. In L. R. Squire \& N. Butters (Eds.), Neuropsychology of memory (pp. 45-54). New York: Guilford Press.

Cermak, L. S., \& O'Connor, M. (1983). The anterograde and retrograde retrieval ability of a patient with amnesia due to encephalitis. Neuropsychologia, 21, 213-234.

Conway, M. A. (1987). Verifying autobiographical facts. Cognition, 26, 39-58.

Crovitz, H. F., \& Quina-Holland, K. (1976). Proportion of episodic memories from early childhood by years of age. Bulletin of the Psychonomic Society, 7, 61-62.

Crovitz, H. F., \& Schiffman, H. (1974). Frequency of episodic memories as a function of their age. Bulletin of the Psychonomic Society, 4(5B), 517-518.

Damasio, A. R., \& Anderson, S. W. (1993). The frontal lobes. In K. M. Heilman \& E. Valenstein (Eds.), Clinical neuropsychology (pp. 409-560). New York: Oxford University Press.

Damasio, A. R., Damasio, H., \& Van Hoesen, G. W. (1982). Prosopagnosia: Anatomical basis and behavioral mechanisms. Neurology, 32, 331-341.

Edwards, A. L. (1970). The measurement of personality traits by scales and inventories. New York: Holt, Rinehart \& Winston.

Engel, M. (1959). The stability of the self-concept in adolescence. Journal of Abnormal and Social Psychology, 58, 211-215.

Evans, J., Wilson, B., Wraight, E. P., \& Hodges, J. R. (1993). Neuropsychological and SPECT scan findings during and after transient global amnesia: Evidence for the differential impairment of remote episodic memory. Journal of Neurology, Neurosurgery, and Psychiatry, 56, 1227-1230.

Farah, M. J. (1988). Is imagery really visual? Overlooked evidence from neuropsychology. Psychological Review, 95, 307-317.

Galton, F. (1879). Psychometric experiments. Brain, 2, 149-162.

Gazzaniga, M.S. (Ed.). (1995). The cognitive neurosciences. Cambridge, MA: MIT Press.

Glanzer, M., \& Cunitz, A. R. (1966). Two storage mechanisms in free recall. Journal of Verbal Learning and Verbal Behavior, 5, 351-360.

Goldstein, F. C., Levin, H. S., \& Boake, C. (1989). Conceptual encoding following severe closed head injury. Cortex, 25, 541-554. 
Goldstein, K. (1995). The organism. New York: Zone Books. (Original work published 1934)

Grice, H. P. (1941). Personal identity. Mind, 50, 330-350.

Grossi, D., Trojano, L., Grasso, A., \& Orsini, A. (1988). Selective "semantic amnesia" after a closed-head injury. A case report. Cortex, 24, 457-464.

Heilman, K. M., \& Valenstein, E. (1993). Clinical neuropsychology (3rd ed.). New York: Oxford University Press.

Hodges, J. R., \& Ward, C. D. (1989). Observations during transient global amnesia. Brain, 112, 595-620.

Hume, D. A. (1817). A treatise of human nature. London: Thomas \& Joseph Allman. (Original work published 1739)

James, W. (1890). The principles of psychology (Vol. 1). New York: Holt.

Jankowiak, J., Kinsbourne, M., Shalev, R., \& Bachman, D. L. (1992). Preserved visual imagery and categorization in a case of associative visual agnosia. Journal of Cognitive Neuroscience, 4, 119-131.

Keenan, J. M. (1993). An exemplar model can explain Klein and Loftus' results. In T. K. Srull \& R. S. Wyer (Eds.), Advances in social cognition (Vol. 5, pp. 69-77). Hillsdale, NJ: Erlbaum.

Kihlstrom, J. F., Cantor, N., Albright, J. S., Chew, B. R., Klein, S. B., \& Niedenthal, P. M. (1988). Information processing and the study of the self. In L. Berkowitz (Ed.), Advances in experimental social psychology (Vol. 21, pp. 145-178). San Diego, CA: Academic Press.

Kihlstrom, J. F., \& Hastie, R. (in press). Mental representations of self and others. In S. R. Briggs, R. Hogan, \& W. H. Jones (Eds.), Handbook of personality psychology. San Diego, CA: Academic Press.

Kihlstrom, J. F., \& Klein, S. B. (1994). The self as a knowledge structure. In R. S. Wyer \& T. K. Srull (Eds.), Handbook of social cognition: Vol. 1. Basic processes (pp. 153-208). Hillsdale, NJ: Erlbaum.

Kihlstrom, J. F., \& Klein, S. B. (in press). Self-knowledge and self-awareness. In J. G. Snodgrass \& R. L. Thompson (Eds.), Annals of the New York Academy of Sciences. The self across psychology: Self-recognition, self-awareness, and the self concept. New York: New York Academy of Sciences.

Kihlstrom, J. F., \& Tobias, B. A. (1991). Anosognosia, consciousness, and the self. In G. P. Prigatano \& D. L. Schacter (Eds.), Awareness of deficit following brain injury: Theoretical and clinical aspects (pp. 198-222). New York: Oxford University Press.

Kinsbourne, M. (1987). Brain mechanisms and memory. Human Neurobiology, 6, 81-92.

Kinsbourne, M., \& Wood, F. (1975). Short-term memory processes and the amnesic syndrome. In D. Deutsch \& J. A. Deutsch (Eds.), Short-term memory (pp. 257-291). New York: Academic Press.

Kirby, D. M., \& Gardner, R. C. (1972). Ethnic stereotypes: Norms on 208 words typically used in their assessment. Canadian Journal of Psychology, 26, 140-154.

Klein, S. B., \& Loftus, J. (1990a). Rethinking the role of organization in person memory: An independent trace storage model. Journal of Personality and Social Psychology, 59, 400-410.

Klein, S. B., \& Loftus, J. (1990b). The role of abstract and exemplar-based knowledge in self-judgments: Implications for a cognitive model of the self. In T. K. Srull \& R. S. Wyer (Eds.), Advances in social cognition (Vol. 3, pp. 131-139). Hillsdale, NJ: Erlbaum.

Klein, S. B., \& Loftus, J. (1993a). Behavioral experience and trait judgments about the self. Personality and Social Psychology Bulletin, 19, 740-745.

Klein, S. B., \& Loftus, J. (1993b). The mental representation of trait and autobiographical knowledge about the self. In T. K.
Srull \& R. S. Wyer (Eds.), Advances in social cognition (Vol. 5 , pp. 1-49). Hillsdale, NJ: Erlbaum.

Klein, S. B., Loftus, J., \& Burton, H. (1989). Two self-reference effects: The importance of distinguishing between self-descriptiveness judgments and autobiographical retrieval in self-referent encoding. Journal of Personality and Social Psychology, 56, 853-865.

Klein, S. B., Loftus, J., \& Plog, A. E. (1992). Trait judgments about the self: Evidence from the encoding specificity paradigm. Personality and Social Psychology Bulletin, 18, 730-735.

Klein, S. B., Loftus, J., \& Sherman, J. W. (1993). The role of summary and specific behavioral memories in trait judgments about the self. Personality and Social Psychology Bulletin, 19, 305-311.

Klein, S. B., Loftus, J., Trafton, R. G., \& Fuhrman, R. W. (1992). The use of exemplars and abstractions in trait judgments: A model of trait knowledge about the self and others. Journal of Personality and Social Psychology, 63, 739-753.

Kolb, B., \& Whishaw, I. Q. (1990). Fundamentals of human neuropsychology (3rd ed). San Francisco: Freeman.

Kopelman, M. D. (1994). The autobiographical memory interview (AMI) in organic and psychogenic amnesia. Memory, 2, 211-235.

Kopelman, M. D., Wilson, B. A., \& Baddeley, A. D. (1989). The autobiographical memory interview: A new assessment of autobiographical and personal semantic memory in amnesic patients. Journal of Clinical and Experimental Neuropsychology, 11, 724-744.

Lazarus, R. S. (1984). On the primacy of cognition. American Psychologist, 39, 124-129.

Levin, H. S. (1989). Memory deficit after closed-head injury. Journal of Clinical and Experimental Neuropsychology, 12, 129-153.

Levin, H. S., High, W. M., Meyers, C. A., Von Laufen, A., Hayden, M. E., \& Eisenberg, H. M. (1985). Impairment of remote memory after closed head injury. Journal of Neurology, Neurosurgery, and Psychiatry, 48, 556-563.

Locke, J. (1731). An essay concerning human understanding. London: Edmund Parker. (Original work published 1690)

Locksley, A., \& Lenauer, M. (1981). Considerations for a theory of self-inference processes. In N. Cantor \& J.F. Kihlstrom (Eds.), Personality, cognition, and social interaction (pp. 263277). Hillsdale, NJ: Erlbaum.

Lucchelli, F., Muggia, S., \& Spinnler, H. (1995). The "Petites Madeleines" phenomenon in two amnesic patients: Sudden recovery of forgotten memories. Brain, 118, 167-183.

Luria, A. R. (1966). Human brain and psychological processes. New York: McGraw-Hill.

MacKinnon, D. F., \& Squire, L. R. (1989). Autobiographical memory and amnesia. Psychobiology, 17, 247-256.

Macmillan, M. B. (1986). A wonderful journey through skull and brains: The travels of Mr. Gage's tamping iron. Brain and Cognition, 5, 67-107.

Martin, E. (1971). Verbal learning theory and independent retrieval phenomena. Psychological Review, 78, 314-332.

Martin, E. (1972). Stimulus encoding in learning and transfer. In A. W. Melton \& E. Martin (Eds.), Coding process in human memory (pp. 59-84). New York: Wiley.

McCrae, R. R. (1982). Consensual validation of personality traits: Evidence from self-reports and ratings. Journal of Personality and Social Psychology, 43, 293-303.

McGlynn, S. M., \& Schacter, D. L. (1989). Unawareness of deficits in neuropsychological syndromes. Journal of Clinical and Experimental Neuropsychology, 11, 143-205. 
Milner, B., Corkin, S., \& Teuber, H. L. (1968). Further analysis of the hippocampal amnesic syndrome: 14-year follow up study of H.M. Neuropsychologia, 6, 215-234.

Mortimer, J. T., \& Lorence, J. (1981). Self-concept stability and change from late adolescence to early childhood. Research in Community and Mental Health, 2, 5-42.

Murdock, B. B., Jr. (1962). The serial position effect of free recall. Journal of Experimental Psychology, 64, 482-488.

Neisser, U. (1986). Nested structures in autobiographical memory. In D. C. Rubin (Ed.), Autobiographical memory (pp. 71-81). New York: Cambridge University Press.

O'Malley, P., \& Bachman, J. (1983). Self-esteem: Change and stability between the ages 13 and 23. Developmental Psychology, 19, 257-268.

Parkin, A. J. (1993). Memory. Cambridge, MA: Blackwell.

Polster, M. R., Nadel, L., \& Schacter, D. L. (1991). Cognitive neuroscience analyses of memory: A historical perspective. Journal of Cognitive Neuroscience, 3, 95-116.

Ribot, T. (1882). Diseases of memory. New York: D. Appleton and Company.

Robinson, J. A. (1976). Sampling autobiographical memory. Cognitive Psychology, 8, 578-595.

Roediger, H. L., \& Blaxton, T. A. (1987). Retrieval modes produce dissociations in memory for surface information. In D. Gorfein \& R. R. Hoffman (Eds.), Memory and cognitive processes: The Ebbinghaus centennial conference (pp. 349-379). Hillsdale, NJ: Erlbaum.

Roediger, H. L., Weldon, M. S., \& Challis, B. H. (1988). Explaining dissociations between implicit and explicit measures of retention: A processing account. In H. L. Roediger \& F. I. M. Craik (Eds.), Varieties of memory and consciousness: Essays in honor of Endel Tulving (pp. 3-41). Hillsdale, NJ: Erlbaum.

Rubin, D. C. (1982). On the retention function for autobiographical memory. Journal of Verbal Learning and Verbal Behavior, $21,21-38$.

Rubin, D. C., Wetzler, S. E., \& Nebes, R. D. (1986). Autobiographical memory across the life span. In D. C. Rubin (Ed.), Autobiographical memory (pp. 202-221). New York: Cambridge University Press.

Russell, W. R. (1935). Amnesia following head injuries. Lancet, 2, $762-763$.

Russell, W. R. (1971). The traumatic amnesias. London: Oxford University Press.

Russell, W. R., \& Nathan, P. W. (1946). Traumatic amnesia. Brain, 69, 280-300.

Sacks, O. (1974). Awakenings. Garden City, NY: Doubleday.

Sacks, O. (1985). The man who mistook his wife for a hat. New York: Doubleday.

Sacks, O. (1995). An anthropologist on Mars: Seven paradoxical tales. New York: Knopf.

Schacter, D. L., \& Crovitz, H. F. (1977). Memory function after closed head injury: A review of the quantitative research. Cortex, 13, 150-176.

Schacter, D. L., Kihlstrom, J. F., Kihlstrom, L. C., \& Berren, M. B. (1989). Autobiographical memory in a case of multiple personality disorder. Journal of Abnormal Psychology, 98, 508-514.

Schacter, D. L., \& Tulving, E. (1982). Memory, amnesia, and the episodic/semantic distinction. In R. L. Isaacson \& N. E. Spear (Eds.), The expression of knowledge (pp. 33-65). New York: Plenum Press.

Schacter, D. L., \& Tulving, E. (Eds.). (1994). Memory systems 1994. Cambridge, MA: MIT Press.

Schacter, D. L., Wang, P. L., Tulving, E., \& Freedman, M. (1982).
Functional retrograde amnesia: A quantitative case study. Neuropsychologia, 20, 523-532.

Schell, T. L., Klein, S. B., \& Babey, S. H. (1996). Testing a hierarchical model of self-knowledge. Psychological Science, 7, 170-173.

Schneider, D. J., Roediger, H. L., \& Kahn, M. (1993). Diverse ways of accessing self-knowledge: Comment on Klein and Loftus. In T. K. Srull \& R. S. Wyer (Eds.), Advances in social cognition (Vol. 5, pp. 123-136). Hillsdale, NJ: Erlbaum.

Scoville, W. B., \& Milner, B. (1957). Loss of recent memory after bilateral hippocampal lesions. Journal of Neurology, Neurosurgery, \& Psychiatry, 20, 11-21.

Sherman, J. W., \& Klein, S. B. (1994). Development and representation of personality impressions. Journal of Personality and Social Psychology, 67, 972-983.

Shoemaker, S. (1963). Self-knowledge and self-identity. Ithaca, NY: Cornell University Press.

Sisler, G., \& Penner, H. (1975). Amnesia following severe head injury. Canadian Psychiatric Association Journal, 20, 333-336.

Tulving, E. (1983). Elements of episodic memory. New York: Oxford University Press.

Tulving, E. (1989). Remembering and knowing. American Scientist, 77, 361-367.

Tulving, E. (1991). Concepts of human memory. In L. R. Squire, N. M. Weinberger, G. Lynch, \& J. L. McGaugh (Eds.), Memory: Organization and locus of change (pp. 3-32). New York: Oxford University Press.

Tulving, E. (1993). Self-knowledge of an amnesic is represented abstractly. In T. K. Srull \& R. S. Wyer (Eds.), Advances in social cognition (Vol. 5, pp. 147-156). Hillsdale, NJ: Erlbaum.

Tulving, E., Hayman, C. A. G., \& Macdonald, C. A. (1991). Longlasting perceptual priming and semantic learning in amnesia: A case experiment. Journal of Experimental Psychology: Learning, Memory, and Cognition, 17, 595-617.

Tulving, E., Schacter, D. L., McLachlan, D. R., \& Moscovitch, M. (1988). Priming of semantic autobiographical knowledge: A case study of retrograde amnesia. Brain and Cognition, 8, 3-20.

Van der Linden, M., Brédart, S., Depoorter, N., \& Coyette, F. (1996). Semantic memory and amnesia: A case study. Cognitive Neuropsychology, 13, 391-413.

Vargha-Khadem, F., Issacs, E., \& Mishkin, M. (1994). Agnosia, alexia and a remarkable form of amnesia in an adolescent boy. Brain, 117, 683-703.

Watkins, M. J. (1977). The intricacy of memory span. Memory \& Cognition, 5, 529-534.

Waugh, N. C., \& Norman, D. A. (1965). Primary memory. Psychological Review, 72, 89-104.

Whitty, C. W. M., \& Zangwill, O. L. (1977). Traumatic amnesia. In C. W. M. Whitty \& O. L. Zangwill (Eds.), Amnesia (2nd ed., pp. 118-135). London: Butterworths.

Wiggins, J. S. (1968). Personality structure. Annual Review of Psychology, 19, 293-350.

Wiggins, J. S. (1973). Personality and prediction: Principles of personality assessment. Reading, MA: Addison-Wesley.

Williams, M., \& Zangwill, O. L. (1952). Memory deficits after head injury. Journal of Neurology, Neurosurgery, and Psychiatry, 15, 54-58.

Wilson, B., \& Baddeley, A. D. (1988). Semantic, episodic, and autobiographical memory in a postmeningitic amnesic patient. Brain \& Cognition, 8, 31-46.

Wood, F., Ebert, V., \& Kinsbourne, M. (1982). The episodicsemantic memory distinction in memory and amnesia: Clinical and experimental observations. In L. S. Cermak (Ed.), 
Human memory and amnesia (pp. 167-193). Hillsdale, NJ: Erlbaum.

Yarnell, P. R., \& Lynch, S. (1970). Retrograde memory immediately after concussion. Lancet, 1, 863-864.

Zajonc, R. B. (1980). Feeling and thinking: Preferences need no inferences. American Psychologist, 35, 151-175.

Zajonc, R. B. (1984). On the primacy of affect. American Psychologist, 39, 117-123.
Zola-Morgan, S., Cohen, N. J., \& Squire, L. R. (1983). Recall of remote episodic memory in amnesia. Neuropsychologia, 21, $487-500$.

Received October 2, 1995

Revision received November 30, 1995

Accepted November 30, 1995

\section{Call for Nominations}

The Publications and Communications Board has opened nominations for the editorship of Developmental Psychology for the years 1999-2004. Carolyn Zahn-Waxler, PhD, is the incumbent editor.

Candidates should be members of APA and should be available to start receiving manuscripts in early 1998 to prepare for issues published in 1999 . Please note that the P\&C Board encourages participation by members of underrepresented groups in the publication process and would particularly welcome such nominees. Self nominations are also encouraged.

To nominate candidates, prepare a statement of one page or less in support of each candidate and send to

Janet Shibley Hyde, PhD, Search Committee Chair

c/o Lee Cron, P\&C Board Search Liaison

American Psychological Association

750 First Street, NE, Room 2004

Washington, DC 20002-4242

Members of the search committee are Bennett Bertenthal, $\mathrm{PhD}$; Susan Crockenberg, $\mathrm{PhD}$; Margaret Spencer, PhD; and Esther Thelen, PhD.

First review of nominations will begin December 9, 1996. 